\title{
Vulnerabilidade do consumidor frente às influências digitais: Um estudo à luz do Código de Defesa do Consumidor Brasileiro de 1990
}

\section{Vulnerability of the consumer to digital influences: A study in light of the Brazilian Consumer Protection Code of 1990}

\author{
Caroline de Alencar Torquato ${ }^{1 *}$, Alyne Andrelyna Lima Rocha Calou ${ }^{1}$, Francisco Renato Silva
} Ferreira$^{1}$, Miguel Melo Ifadireó ${ }^{2}$, Christiano Siebra Felício Calou${ }^{1}$, Tamyris Madeira de Brito ${ }^{1}$

\begin{abstract}
RESUMO
O presente estudo busca demonstrar a vulnerabilidade do consumidor em decorrência das mídias sociais, e, na hipótese, discutir a responsabilização do Influenciador Digital pelos eventuais prejuízos que ele causar em função de suas publicidades. Com isso, a metodologia utilizada se baseia de modo geral em uma pesquisa de revisão bibliográfica, de cunho qualitativo, dentro do ramo do Direito do Consumidor, como uma ciência social aplicada, possuindo natureza básica, mas também é usado o método de pesquisa exploratória, a fim de buscar soluções sobre a problemática desencadeada. Os resultados obtidos a partir do estudo se mostram importantes, tendo em vista a inexistência de legislação específica para regular as situações conflituosas em que o consumidor está corriqueiramente sendo submetido, onde o maior papel do estudo foi compreender de que maneira o direito pode, nessas condições, agir para equilibrar os conflitos e proteger o direito lesado em decorrência das relações de consumo proporcionadas pela internet.
\end{abstract}

Palavras-chave: Publicidade; Responsabilidade; Influenciadores; Consumidores.

\begin{abstract}
This study seeks to demonstrate the consumer vulnerability due to social media, and, in hypothesis, discuss the liability of the Digital Influencer for any damage he causes due to his advertisements. Thus, the methodology used is based, in general, on a bibliographic review research, qualitative in nature, within the branch of Consumer Law, as an applied social science, having a basic nature, but the exploratory research method is also used, in order to seek solutions to the problem triggered. The results obtained from the study have shown to be important, considering the inexistence of specific legislation to regulate the conflicting situations in which the consumer is routinely being subjected, where the major role of the study was to understand how the law can, under these conditions, act to balance conflicts and protect the right injured as a result of consumer relations provided by the Internet.
\end{abstract}

Keywords: Advertising; Responsibility; Influencers; Consumers.

\footnotetext{
${ }^{1}$ Centro Universitário Doutor Leão Sampaio - (UNILEÃO).

*E-mail: norf20@hotmail.com

${ }^{2}$ Universidade de Pernambuco - (UPE)
} 


\section{INTRODUÇÃO}

No ano de 2021, com os avanços tecnológicos, restou nitidamente presente na sociedade a extrema necessidade em estar conectado às mídias sociais, apresentando-se, portanto, a diversidade de formas de interação social, o que, por conseguinte, acabou por influenciar nas mudanças comportamentais, focadas no que o sociólogo Bauman (2007) chamou de Cultura do Imediatismo, baseada na liquidez, na ansiedade em que se vive, que decorre da velocidade para saber, sentir, resolver as coisas de modo geral, com toda uma fluidez, incerteza e insegurança, que o autor declarou como sendo a marca deste século.

Desta forma, a sociedade moderna também é tida como uma sociedade que preza pela praticidade, a qual engloba todas as ações cotidianas. Com isso, atendendo a essa necessidade do ser prático, as indústrias de comércio não se pouparam, viram a internet como o meio ideal para promover propagandas em massa, usaram das formas mais inimagináveis, possibilitaram às empresas novos jeitos de disseminar sua marca ou produto e guiaram a população ao consumo exacerbado.

Ao analisar o cenário de vendas on-line, é visto que as formas de propagação das propagandas estão constantemente se expandindo e, em decorrência disso, a internet vem se tornando o seu aparato principal. E eis que desse meio emerge uma nova profissão que, apesar de seu potencial crescimento, ainda não foi reconhecida como tal pelo Ministério do Trabalho e Emprego, o Influenciador Digital.

No exercício de seu trabalho, o Influenciador usa das plataformas virtuais para recomendar produtos e serviços que a ele são submetidos, seja de forma contratual, seja em troca de permuta, na maioria das vezes não tendo tempo de verificar a autenticidade e eficiência do que está recomendando, prevalecendo unicamente o interesse em cumprir o que foi acordado, sem se preocupar com quem irá consumir.

Logo, tendo em vista o expressivo percentual da população que é adepta ao uso das redes sociais, tornando-se um alvo da provável influência de consumo do que lhe é indicado, é possível chegar à seguinte problemática: Como se dá a responsabilidade civil do influenciador digital na sociedade de consumo?

Com isso, este artigo tem a pretensão de ponderar sobre esse tipo de agente social, com o objetivo geral de investigar, sob uma perspectiva jurídica, como se dá a 
responsabilidade civil do influenciador digital na sociedade de consumo, sob a ótica do Código de Defesa do Consumidor.

E nesse mesmo contexto, são objetivos específicos desse estudo, compreender o fenômeno do influenciador digital e sua inserção no mercado de consumo, examinar, por meio das fontes do direito, a possibilidade de responsabilização dos influenciadores e apresentar o corolário da responsabilidade civil do influenciador digital.

Sendo a presente pesquisa um levantamento crítico acerca da exposição pelas pessoas, na qualidade de internautas e consumidores, esta propõe como justificativa a reflexão e a busca pela compreensão de como o direito pode servir de auxílio para resguardar os direitos da população, no que tange às relações de consumo, utilizando-se dos princípios norteadores do direito do consumidor, da lei e dos meios necessários para fazerem esclarecidas as controvérsias quanto ao tema pautado e tornar as experiências com compras on-line mais agradáveis e, no que couber, evitar possíveis transtornos.

Ressalta-se que a metodologia desta pesquisa foi elaborada por meio do Código de Defesa do Consumidor e do Código Civil, onde o desenvolvimento dela se manifestará com uma abordagem qualitativa, em que se é pretendida a compreensão e a profundidade no assunto abordado, possuindo, assim, natureza básica, que implica em trazer e discutir conhecimentos novos e úteis para o avanço da Ciência, sem a previsão de aplicação prática.

Quanto aos objetivos, são incorporados no método de pesquisa exploratória, em razão da limitada exploração do tema por outros pesquisadores até o presente momento. Sobre esse método, Antônio Carlos Gil preceitua:

\begin{abstract}
As pesquisas exploratórias têm como principal finalidade desenvolver, esclarecer e modificar conceitos e ideias, tendo em vista a formulação de problemas mais precisos ou hipóteses pesquisáveis para estudos posteriores. De todos os tipos de pesquisa, estas são as que apresentam menor rigidez no planejamento. Habitualmente envolvem levantamento bibliográfico e documental, entrevistas não padronizadas e estudos de caso. Procedimentos de amostragem e técnicas quantitativas de coleta de dados não são costumeiramente aplicados nestas pesquisas. (GIL, 2008, p. 27)
\end{abstract}

O procedimento técnico se dará de tal forma que, será realizada uma revisão bibliográfica, situação essa que será feita uma análise do Código de Defesa do Consumidor e do Código Civil, no que se faz pautar sobre responsabilidade no consumo. Bem como, revisará pesquisas científicas de distintos autores sobre temas que se assemelham ao tema apresentado nesta pesquisa. 
E não menos importante, este trabalho colherá informações através do mecanismo da internet, tomando por base alguns artigos e notícias de revista, que anteriormente vieram à discutir o tema, com a finalidade de enriquecer a pesquisa e o conhecimento que será repassado.

Esta pesquisa também faz-se moldar pelo método dedutivo de pesquisa, que segundo Antônio Carlos Gil:

\begin{abstract}
O método dedutivo, de acordo com a acepção clássica, é o método que parte do geral e, a seguir, desce ao particular. Parte de princípios reconhecidos como verdadeiros e indiscutíveis e possibilita chegar a conclusões de maneira puramente formal, isto é, em virtude unicamente de sua lógica. É o método proposto pelos racionalistas (Descartes, Spinoza, Leibniz), segundo os quais só a razão é capaz de levar ao conhecimento verdadeiro, que decorre de princípios a priori evidentes e irrecusáveis. (GIL, 2008, p. 9)
\end{abstract}

Por conseguinte, a finalidade deste estudo foi usar dos métodos para investigar como o direito pode atuar para solucionar um tipo específico de conflitos, surgidos com a expansão da teia de consumo que nos envolve, contribuindo efetivamente para simplificar situações inconvenientes durante a aquisições de bens ou serviços, em que nós consumidores estamos sujeitos.

A primeira seção do referencial teórico, intitulada A Publicidade e Propaganda, o Influenciador Digital e a Sociedade Consumerista, propõe um breve estudo acerca da publicidade e propaganda, desde os tempos antigos aos mais atuais, a fim de poder entender o papel do influenciador digital, como um sujeito dotado de capacidade para manipulação das mídias, assim como de propagar e influenciar o consumo.

A segunda seção do referencial teórico, intitulada de As Influências Digitais e os Prejuízos da Publicidade Clandestina, consiste em avaliar os reflexos que as influências causam na sociedade, dentro do aspecto virtual, onde os seguidores desses tais influenciadores, encontram-se em posição de consumidores e acabam se tornando vulneráveis pela falta de informação, no sentido de que na maioria das vezes não se possibilita a compreensão de que o que está sendo propagado a eles trata-se, na verdade, de uma publicidade e não de uma genuína recomendação.

Por fim, a terceira seção do referencial teórico, sob o título de A Responsabilidade Civil do Influenciador Digital Segundo a Interpretação do Código de Defesa do Consumidor. Neste tópico é feita uma análise acerca da possibilidade de responsabilização do Influenciador Digital e de que modo ela poderia se dar, a fim de que os danos causados ao consumidor possam ser reparados, tomando como fonte de pesquisa, o Código de Defesa do Consumidor e o Código Civil, para fins investigativos. 


\section{A PUBLICIDADE E PROPAGANDA, O INFLUENCIADOR DIGITAL E A SOCIEDADE CONSUMERISTA}

Observa-se que, para o sujeito sofrer qualquer tipo de influência por um anúncio ou propaganda, basta apenas o convívio no meio social. Porém, as estratégias de Publicidade e Propaganda são na verdade costumes bem mais antigos do que parecem. Pelo que informa Eloá Muniz (2004), foi na Antiguidade Clássica quando surgiram os seus primeiros vestígios, conforme restou demonstrado por tabuletas descobertas em Pompéia, onde essas tabuletas anunciavam os combates de gladiadores, vendas de escravos, dentre outros. Foi se transformando juntamente com as demandas sociais, passou de jornais à empresas de publicidade e comércio, rádio, televisão, até o que nós conhecemos hoje como sendo um dos mais importantes meios de disseminação de publicidades, a internet.

Com o surgimento da internet e a criação de sites de proporção mundial, como eBay e Amazon, o E-Commerce ou simplesmente, Comércio Eletrônico, passou a conquistar a sua popularidade com promessas de praticidade e conveniência durante a aquisição de bens e serviços. Além do E-Commerce, a internet avança em todos os quesitos, facilitando não apenas as negociações, como também a comunicação, por meio das redes sociais. A publicidade, desde então, tem sido a principal aliada das empresas na divulgação de seu produto ou serviço e as grandes empresas de publicidade, por sua vez, viram as redes sociais como uma ferramenta perfeita para a promoção de vendas, já que grande parte da população se rendeu ao uso de aplicativos de mídia social, tais como o Facebook e o Instagram.

Com o passar do tempo, pessoas foram ganhando fama e visibilidade através das redes sociais, por estarem mostrando o seu dia a dia, moda, saúde, viagens, compras e etc. Tal fato acabou gerando interesse e busca por quem via e acompanhava o cotidiano dessas pessoas, sendo influenciadas pelo que lhes era mostrado e recomendado. Em razão disso, as marcas viram nessas pessoas uma maneira de potencializar as suas vendas, afinal, segundo os dizeres da sociedade, a melhor propaganda é o Boca a Boca, que o Dicionário Informal (2006) sugere se tratar de uma técnica de propaganda em que as pessoas vão comentando uma para a outra e acabam espalhando a notícia e é, a partir 
disso, que surge a figura do Digital Influencer ou Influenciador Digital, com suas publicidades testemunhais.

Os Influenciadores Digitais, também chamados de Criadores de Conteúdo Digital ou subcelebridades, são figuras públicas que compartilham abertamente as suas vidas nas mídias sociais, especificamente por meio do Instagram, e que, como o próprio nome já sugere, influenciam milhares de pessoas que os espectam, como é o exemplo da personalidade americana Kylie Jenner, que, segundo o seu perfil no site do Instagram, em abril de 2021, contava com mais de 226 milhões de seguidores em sua conta, e do alagoano Carlinhos Maia, com 21,8 milhões de seguidores, que, segundo a página online OFuxico (OFuxico, 2018), em agosto de 2020 atingiu a marca recordista de 2 bilhões de impressões em seu perfil do Instagram e, em 2018, obteve o segundo lugar no ranking de stories mais visualizados do mundo, chegando a receber o título de O Rei do Instagram. (HUGO GLOSS, 2018)

No que diz respeito ao Influenciador Digital, Issaaf Karhawi, et al., em sua obra Tendências em Comunicação Digital, puseram-se a destacar:

\begin{abstract}
A diferença entre um influenciador digital e uma celebridade é justamente o sujeito, o Eu. O influenciador digital, digital influencer, creator, ou a denominação vigente que for, é um sujeito que preserva o seu Eu. Enquanto uma celebridade está distante, sob holofotes, traçando um caminho de sucesso que parece muito distante de quem os assiste no cinema ou na televisão, os influenciadores digitais estão no Facebook, no Instagram, no Snapchat, em espaços ocupados por "pessoas comuns" com quem dialogam em igualdade. É por esse motivo, também, que revistas e sites de veículos tradicionais de mídia não têm a mesma reputação que os influenciadores digitais. A proximidade desses sujeitos de seus públicos, de sua rede, a partir da escrita íntima, do uso da primeira pessoa (no caso dos blogs, Instagram, Twitter) e da pessoalidade cria uma aproximação entre o criador de conteúdo e seus públicos. É nessa sustentação que se ergue o capital simbólico dos blogueiros e, muito fortemente, das blogueiras de moda que são encaradas como melhores amigas de suas leitoras. (KARHAWI, 2016, p. 46-47)
\end{abstract}

Já sob a ótica econômica e empresarial, preceituam Marcos Inácio Severo de Almeida, et al., "influenciadores digitais são formadores de opinião virtuais que representam uma alternativa para empresas que confiam na comunidade reunida em torno desses perfis como público-alvo de divulgação". (ALMEIDA, 2018, p. 16)

Em uma mesma perspectiva, é importante vir a conceituar o que seria Publipost, tendo em vista o caráter da presente pesquisa. O Publipost, ou pela sua forma abreviada, como é mais conhecido, Publi, é o nome que se dá a tática de publicidade, por meio da qual uma marca contrata um influente digital, para produzir um post sobre um determinado produto ou serviço, situação em que se configura na forma de uma 
postagem de foto ou vídeo, podendo ser postada no feed ou no story do Instagram, onde o influenciador aparece satisfeito com o produto ou serviço, dentro de uma produção que simula o uso deste no seu cotidiano. (VULGATA COMUNICAÇÃO E MARKETING, 2019)

Abaixo, é possível identificar, nas figuras 1 e 2, exemplos de publicidades no feed do Instagram de influenciadoras digitais, com e sem a sinalização:

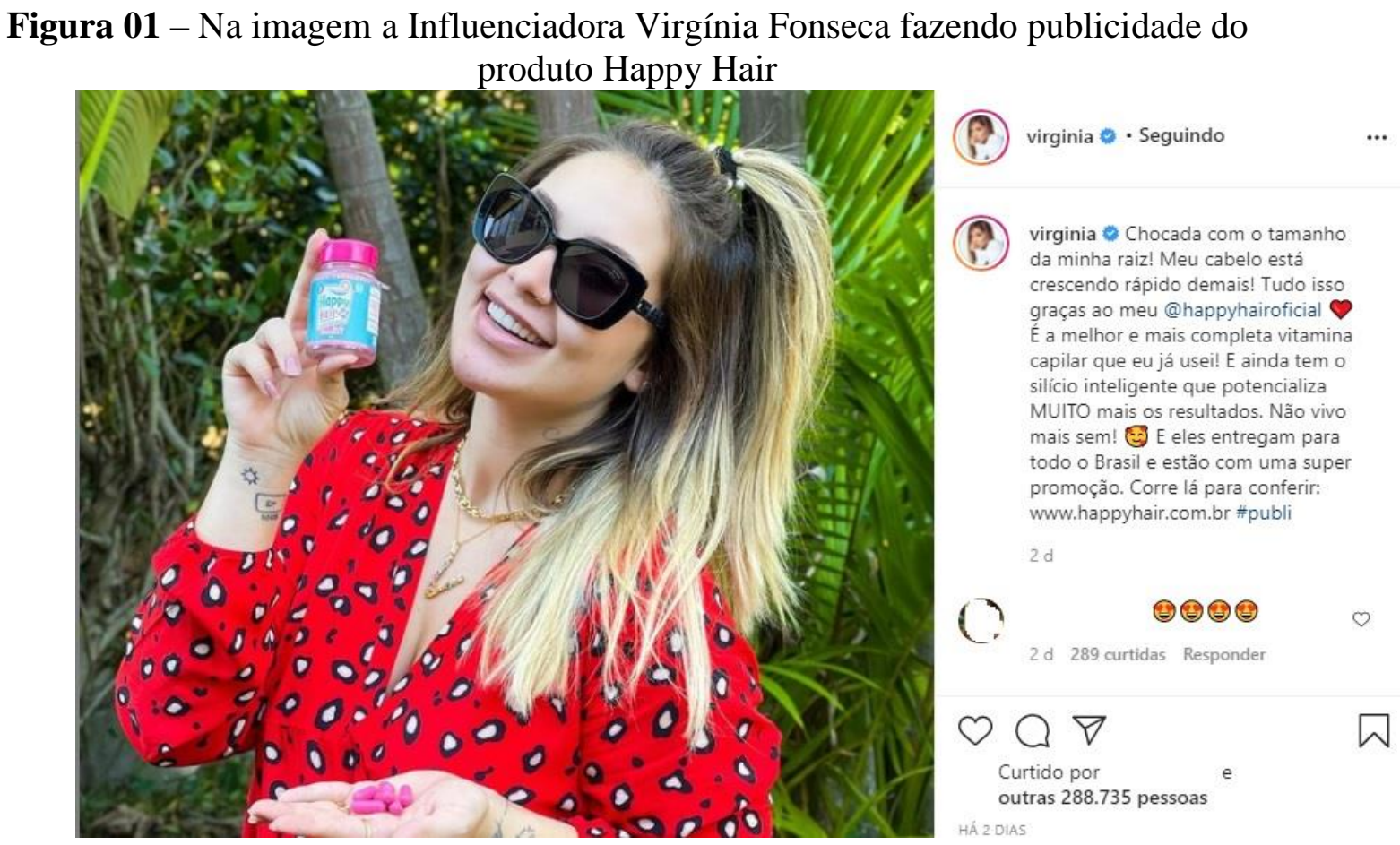

Fonte: Reprodução https://www.instagram.com/p/COtWWlMFdi9/

É possível visualizar na figura de número 01, a influenciadora Virgínia Fonseca fazendo publicidade de uma vitamina capilar, postada no feed do perfil pessoal do Instagram da influenciadora e foi devidamente sinalizada como publicidade pelo marcador \#publi posicionado ao final da legenda. A seguir, será apresentada a figura 02 , retirada de um vídeo da mesma plataforma de mídia social, também postado no feed, agora no perfil da influenciadora Pamela Drudi, no qual é possível notar que se trata de uma publicação ausente de sinalização de marcadores, embora seja uma publicidade, assim como na primeira figura.

Figura 02 - Na imagem a influenciadora Pamela Drudi fazendo publicidade da loja Fashion MakeUp 


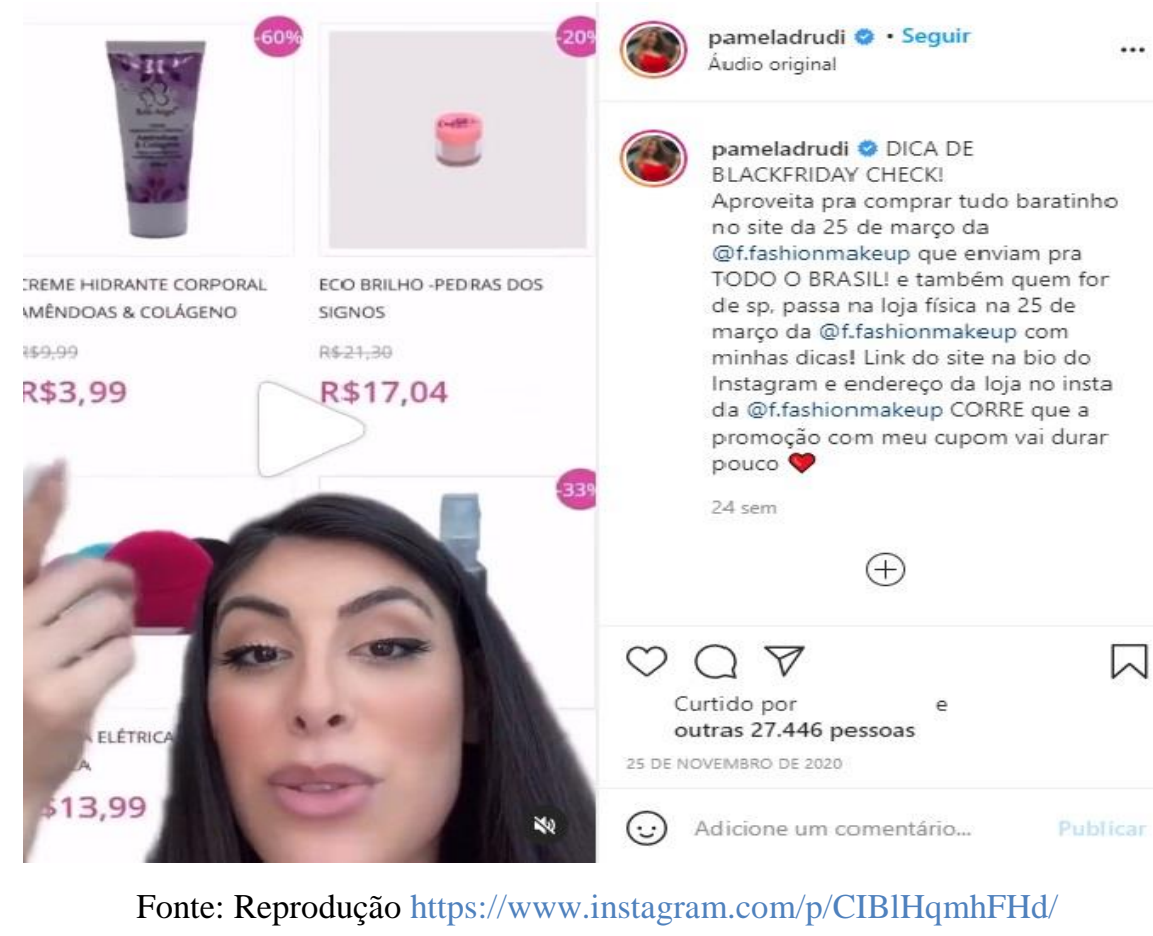

O contrato comumente se dá em troca de permuta (unidades do próprio produto, ou em forma de serviço) ou pagamento em moeda corrente. Em geral, cada influenciador possui sua própria tabela de preço por postagem, mas o que é levado em conta pelas marcas na hora de contratar um influenciador, não é apenas os seus números de seguidores, mas também, o engajamento no seu perfil e a capacidade que ele tem de influenciar.

As empresas têm a possibilidade de utilizar de um serviço chamado Instagram Ads, e manipularem estrategicamente as publicidades, escolhendo o tipo de público, classificando-os em gênero, idade, localidade, idioma, sendo possível também disponibilizar o orçamento e programação desejada, dentre muitas outras funções. (KLICKPAGES, 2021)

\section{AS INFLUÊNCIAS DIGITAIS E OS PREJUÍzOS DA PUBLICIDADE CLANDESTINA}

Foi por intermédio da adoção das mídias sociais como um novo estilo de divulgação de produtos e serviços que surgiu a Publicidade Clandestina, advinda do receio da aversão dos usuários à numerosa quantidade de propaganda que lhes era ofertada, como uma espécie de garantia que o conteúdo anunciado ali fosse consumido, 
e com o intuito de evitar que as pessoas o ignorassem ou, porventura, este acabasse saturado.

Essa modalidade clandestina de publicidade emergiu a partir da ideia de que o caráter apelativo do conteúdo a ser vendido ao público deveria passar despercebido, de uma forma maquiada, a fim de que as pessoas entendessem como a mera indicação ou sugestão de quem o usa e não como uma publicidade, de fato. (DEL MASSO, 2009)

Ocorre que muitos usuários passaram a entender essa tática, nutrindo, assim, o sentimento de engano e frustração, o que fez necessária a sinalização das postagens publicitárias por hashtags, como \#publi ou \#Ad ou até mesmo pelo marcador Parceria Paga acrescido do nome da marca, na tentativa de controlar a situação. Entretanto, ainda é muito corriqueiro se deparar com a Publicidade Clandestina, que, à proposito, adquiriu esse nome por sua prática caminhar em desacordo com o que o Ordenamento Jurídico propõe, podendo-se citar o que preceitua o Código de Defesa do Consumidor:

\footnotetext{
Art. 36. A publicidade deve ser veiculada de tal forma que o consumidor, fácil e imediatamente, a identifique como tal.

Parágrafo único. O fornecedor, na publicidade de seus produtos ou serviços, manterá, em seu poder, para informação dos legítimos interessados, os dados fáticos, técnicos e científicos que dão sustentação à mensagem. (BRASIL, 1990)
}

As publicidades desta espécie têm demandado atenção do Conselho Nacional de Autorregulamentação Publicitária (CONAR, 1980) e provocado disputas no Poder Judiciário, tendo em vista que colocam o consumidor em posição vulnerável, em decorrência do fato de que esse tipo de anúncio tenta vender um produto ou serviço o qual as pessoas acreditam fazer parte da rotina do influenciador, quando, na verdade, em muitas das vezes, eles não chegam a usufruir de fato o produto ou serviço que estão anunciando e não parecem preocupar-se com quem irá consumi-lo, não obstante falem com convicção e persuasão, o que induz os seguidores, que ora se encontram na posição de consumidores, a adquirir algo que não preenche os requisitos de qualidade, expectativa, utilidade, prazo, confiabilidade ou demais elementos ligados ao que o Código de Defesa do Consumidor estipula e que, em numerosas vezes, estes consumidores nem estão cientes de que aquela recomendação tratava-se, na realidade, de uma publicidade. Neste sentido, Paulo Jorge Scartezzini Guimarães, ao fazer uma análise comportamental do consumidor afirmou:

[...] é nesse desbravamento e exploração da mente humana que os publicitários se apoiam e buscam as inspirações para seus anúncios. Criam eles necessidades e após manipulam os consumidores em direção ao produto ou serviço que irá supri-las. Criam efetivamente desejos supérfluos, que, logo 
em seguida, graças às suas técnicas, são transformadas em produtos imprescindíveis. Assim, estão corretos aqueles que, primeiramente, surge o produto ou serviço; depois é que se inventa a necessidade. (GUIMARÃES, 2001, p. 98)

Com isso, resta clara a crítica de Guimarães (2001), segundo a qual os influenciadores digitais também são uma espécie de instrumento de manipulação estratégica das empresas, que têm por finalidade induzir a sociedade ao consumo massivo e desprovido de responsabilidade moral e conscientização, persuadida e atraída com ingenuidade pela imensa vitrine que lhes é imposta diariamente, com o simples uso das redes sociais.

É válido ressaltar que, apesar de inexistir uma legislação que trate especificamente sobre as Influências Digitais, o Código de Defesa do Consumidor e o Conselho Nacional de Autorregulamentação Publicitária (CONAR, 1980) determinam alguns princípios que devem ser aplicados às publicidades criadas pelos influenciadores através das redes sociais, de modo que se preza pelo respeito, honestidade e verdade. Observa-se:

\footnotetext{
Art. $1^{\circ}$ - todo anúncio deve ser respeitador e conformar-se às leis do país; deve, ainda, ser honesto e verdadeiro.

Art. 23 - Os anúncios devem ser realizados de forma a não abusar da confiança do consumidor, não explorar sua falta de experiência ou de conhecimento e não se beneficiar de sua credulidade.

Art. 28 - O anúncio deve ser claramente distinguido como tal, seja qual for a sua forma ou meio de veiculação (CONAR, 1980)
}

Dito isto, destaca-se a importância dos Princípios estabelecidos pelo Código de Defesa do Consumidor, que devem ser observados em face das publicidades, dentre os quais se pode citar o princípio da vinculação, princípio da identificação e o princípio da veracidade e não abusividade.

O princípio da vinculação ou princípio da vinculação contratual da publicidade está inserido no Art. 30 do Código de Defesa do Consumidor (BRASIL, 1990), o qual estabelece que as informações concernentes à publicidade, precisamente vinculam o fornecedor ao cumprimento do que prometem os anúncios, o que faz com que, em situação de não observância, o fornecedor se sujeite ao que dispõe o Art. 35 do CDC (BRASIL, 1990), que traz hipóteses em que o consumidor virá a decidir o que se procederá, dentro do que a lei estabelece, como, por exemplo, a substituição do produto ou serviço, rescisão contratual e cumprimento forçado da obrigação. Por intermédio 
deste princípio, resta clara a preocupação que o direito tem com relação ao poder de influência que a publicidade demanda sobre os consumidores.

No tocante ao princípio da identificação, este requer que a publicidade, em hipótese alguma, deixe de ser reconhecida como tal, devendo ser de fácil identificação pelo consumidor, e proibindo, assim, a prática da publicidade clandestina, técnica também conhecida por merchandising, que diz respeito à forma de fazer publicidade sem demonstrar que a aparição do produto está sendo paga (VERONEZZI, 2009).

E, por fim, no que se refere ao princípio da veracidade e não abusividade, que se consagra no art. $37^{\circ}$ do CDC (BRASIL, 1990), onde a lei faz questão de classificar a publicidade em enganosa e abusiva, cumpre ressaltar que tal princípio veda qualquer forma de publicidade discriminatória, ou que seja capaz de induzir o consumidor ao erro.

\section{A RESPONSABILIDADE CIVIL DO INFLUENCIADOR DIGITAL SEGUNDO A INTERPRETAÇÃO DO CÓDIGO DE DEFESA DO CONSUMIDOR}

Primordialmente, antes de chegar ao ponto chave desta seção, é necessário desmistificar o que seria uma relação de consumo, como um guia para entender o porquê de responsabilizar o Influenciador Digital e qual seria a posição dele dentro dessa relação. Para tanto, o Código de Defesa do Consumidor não chegou a trazer especificamente nenhuma definição de relação de consumo, porém vem a ser subtendida, pois os seus elementos encontram-se compreendidos pelo ordenamento jurídico.

A lei compreende o fornecedor como o polo ativo da relação, sendo toda e qualquer pessoa física ou jurídica que desenvolva atividades regulares e habituais de produção, montagem, criação, construção, transformação, importação, exportação, distribuição e/ou comercialização de produtos ou prestação de serviços (BRASIL,1990). Quanto ao polo passivo, esse é ocupado pelo consumidor, pessoa física ou jurídica que adquire ou utiliza produto ou serviço como destinatário final. Frisa-se, ainda, que a lei é detentora da teoria finalista e esta pressupõe que, para caracterizar um consumidor como destinatário final, o produto ou serviço não deve estar no âmbito de expertise de quem o adquire e deve haver a presença da vulnerabilidade. 
Neste sentido, é importante salientar os tipos de consumidores, a fim de diferenciá-los. Considera-se consumidor final, aquele que adquire um produto para uso habitual próprio ou de sua família, estando esse produto, em seu estado final de comercialização, diferente de uma revenda, por exemplo. Já consumidor por equiparação, é outra espécie de consumidor trazida pelo Código de Defesa do Consumidor e refere-se àqueles que de alguma maneira vierem a intervir na relação de consumo.

E da mesma forma, é fundamental ressaltar, que a doutrina identifica três espécies mais comuns de fornecedores, quais sejam, fornecedor real, fornecedor presumido e fornecedor aparente. O fornecedor real é aquele que está atrelado de forma efetiva ao processo de fabricação do produto, mais especificamente, pode-se citar, a título de exemplo, o fabricante, o produtor e o construtor. Já o presumido atua como um intermediário entre quem fabrica e o consumidor como, por exemplo, o importador, que é um fornecedor por presunção legal. Por fim, o fornecedor aparente, que dá um rótulo aos produtos, associa-se a marca que eles recebem.

Entretanto, além desses três tipos, observa-se, ainda, a existência de uma espécie de fornecedor, nomeado pela doutrina como fornecedor por equiparação. Este derradeiro implica-se em um terceiro ligado à relação de consumo como um intermediário ou ajudante, que contribui para a concretização da relação principal, muito embora atue frente a um consumidor como se fornecedor fosse. Ou seja, ele é o dono da relação conexa e possui uma posição de poder na relação com o consumidor. (MARQUES; BENJAMIM; BESSA; 2007)

Quanto ao objeto da relação jurídica de consumo, este consiste no bem ou serviço a ser adquirido pelo consumidor, ofertado pelo fornecedor. O conceito de produto está contido no $\S 1^{\circ}$ do art. $3^{\circ}$ do CDC: “§ $1^{\circ}$ Produto é qualquer bem, móvel ou imóvel, material ou imaterial” (BRASIL, 1990). E por serviço, o parágrafo $2^{\circ}$, do mesmo diploma legal, estabelece que " $§ 2^{\circ}$ Serviço é qualquer atividade fornecida no mercado de consumo, mediante remuneração, inclusive as de natureza bancária, financeira, de crédito e securitária, salvo as decorrentes das relações de caráter trabalhista". (BRASIL, 1990)

Dessarte, tem-se que para a incidência do Código de Defesa do Consumidor é imprescindível a caracterização da relação jurídica de consumo por todos os seus elementos, tanto no quesito subjetivo, havendo a presença de um consumidor e de um 
fornecedor, quanto objetivo, que é o próprio objeto da relação, podendo ser um produto ou a prestação de um serviço.

Superadas as noções básicas sobre relação de consumo, atenta-se para a hipótese de responsabilização do Influenciador. Assim, para que se possa aferir acerca de sua responsabilização, é indispensável destacar aqui o que seja responsabilidade civil.

Nas palavras de Silvio Rodrigues "A responsabilidade civil é a obrigação que pode incumbir uma pessoa a reparar o prejuízo causado a outra, por fato próprio, ou por fato de pessoas ou coisas que dela dependam" (RODRIGUES, 2003, p).

Nessa perspectiva, mostra-se também importante trazer o entendimento da lei civil a respeito de responsabilidade civil, termos que estabelece o Art. 927 da referida lei:

\footnotetext{
Art. 927. Aquele que, por ato ilícito (arts. 186 e 187), causar dano a outrem, fica obrigado a repará-lo.

Parágrafo único. Haverá obrigação de reparar o dano, independentemente de culpa, nos casos especificados em lei, ou quando a atividade normalmente desenvolvida pelo autor do dano implicar, por sua natureza, risco para os direitos de outrem. (BRASIL, 2002)
}

A reponsabilidade civil pode se dar de várias formas, entretanto, será discorrido de forma breve a sua classificação quanto à culpa e quanto ao dever jurídico violado. $\mathrm{Na}$ responsabilidade civil quanto à culpa do agente, avalia-se a culpa subjetiva e objetiva, sendo que, quando subjetiva, deve conter os elementos dolo ou culpa permeando a conduta do agente que comete o dano. Diferentemente é a responsabilidade civil objetiva, que exige apenas a presença de dano e de nexo causal entre a conduta para que se faça necessária a responsabilidade de reparação do dano.

Já quanto ao dever jurídico violado, pode-se classificar em responsabilidade contratual, quando diante de danos decorrentes de celebração de contrato, e extracontratual, quando não proveniente de negócio jurídico.

Contudo, é a modalidade que afere a culpa do agente que verdadeiramente interessa ao Código de Defesa do Consumidor, pois ele adota a responsabilidade civil objetiva, ou seja, independente de culpa ou dolo. Em seus artigos 12, 13, 14, 18, 19 e 20, o CDC expõe claramente essa responsabilidade objetiva, inclusive solidária, entre os fornecedores de produto e os prestadores de serviço. A exceção de responsabilidade subjetiva trazida pelo Código de Defesa do Consumidor é a concernente aos profissionais liberais que prestam serviço, já que somente respondem mediante prova de culpa. Ela consta no parágrafo $4^{\circ}$ do art. 14, conforme transcrito abaixo: “Art. $14-(\ldots)$ 
$\S 4^{\circ}$ - A responsabilidade pessoal dos profissionais liberais será apurada mediante a verificação de culpa.” (BRASIL, 1990)

Desta forma, considerando o grande poder de persuasão dos Influenciadores Digitais, e, como o próprio nome já sugere, a influência que eles têm, é dever constitucional do Estado garantir a proteção das pessoas que seguem e acompanham a vida desses influenciadores, quando se encontrarem na qualidade de consumidores dos produtos/serviços que lhes são recomendados ou apresentados nas mídias sociais, assim como preconiza o Art. $5^{\circ}$, inciso XXXII, da Constituição Federal:

\footnotetext{
Art. $5^{\circ}$ Todos são iguais perante a lei, sem distinção de qualquer natureza, garantindo-se aos brasileiros e aos estrangeiros residentes no País a inviolabilidade do direito à vida, à liberdade, à igualdade, à segurança e à propriedade, nos termos seguintes:

XXXII - o Estado promoverá, na forma da lei, a defesa do consumidor; (BRASIL, 1990)
}

Dito isto, surgem questões quanto a ideia de responsabilizar o influenciador, gerando uma certa polêmica entre a jurisprudência e a alguns autores. Guimarães (2001) observou que, a princípio, pode não parecer coerente a ideia de responsabilizar as celebridades digitais, visto não terem relação direta com o bem anunciado, divulgando nas publicidades texto criado por outrem, como é a tarefa que se atribui aos publicitários. Mas, o autor entende que toda atividade profissional gera responsabilidade civil por danos circunstanciais, sendo obrigado a indenizar os prejudicados dentro dessa relação.

Foi nesse sentido que Gasparatto, Freitas e Efing concluíram que deve, sim, ser atribuída ao Influenciador Digital a responsabilidade civil com a finalidade de que os prejuízos que eles, porventura, vierem a causar aos consumidores, sejam reparados. Observe-se:

Deve-se atribuir aos influenciadores responsabilidade de reparação frente aos consumidores, em razão da indicação de produtos e serviços. Eis que tais pessoas possuem grande poder de influência, além de contarem com a confiança de seus seguidores. (GASPARATTO, FREITAS e EFING, 2019, p. 79)

Não obstante existir na sociedade moderna esse tipo de influência, o que se exige do Estado é apenas a devida proteção dentro das relações de consumo, sem abolir esse método de publicidade e propaganda, garantindo também que a liberdade de expressão seja exercida e a preservação do que estabelece o Art. 220, caput, da CF, onde diz que: “Art. 220. A manifestação do pensamento, a criação, a expressão e a informação, sob qualquer forma, processo ou veículo, não sofrerão qualquer restrição, 
observado o disposto nesta Constituição." (BRASIL, 1990). Da mesma forma, completa Marcos Daniel Veltrini Ticianelli, no que se refere a publicidade e a propaganda, afirmando que "precisam existir, o contrário seria negar o acesso à informação às pessoas, comprometendo os conceitos de liberdade e democracia. A publicidade é indissociável da liberdade de expressão.” (TICIANELLI, 2007, p. 71)

O Código de Defesa do Consumidor, consolidado na Lei $\mathrm{n}^{\circ} 8.078$ de 11 de setembro de 1990, discorre sobre os direitos de proteção ao consumidor no âmbito infraconstitucional, onde em seu art. $4^{\circ}$, inciso I, estabeleceu o princípio da política nacional das relações de consumo o princípio da vulnerabilidade, que expressa o reconhecimento da vulnerabilidade do consumidor, sendo ele a parte mais frágil da relação jurídica de consumo.

Com isso, sendo a responsabilidade civil do Influenciador, um assunto que vem sendo debatido e que gera controvérsias em razão da divergência nos posicionamentos de doutrinadores e estudiosos, analisa a hipótese de culpa objetiva do influenciador. Pela interpretação do disposto no artigo 927 e no artigo 187 do Código Civil (BRASIL, 2002), já vistos anteriormente, diante da situação temática de que trata o presente estudo, é entendido que vem a cometer um ato ilícito o influenciador, titular de um direito, que durante o seu exercício, qual seja, a liberdade de expressão, acaba excedendo, manifestamente, os limites impostos pelo seu fim econômico ou social, pela boa-fé ou pelos bons costumes, ou seja, quando a publicidade gerar danos a outrem. Seguindo esse mesmo raciocínio, complementa Guimarães em sua afirmação:

Devem ser aplicadas às celebridades todas as diretrizes do CDC, inclusive no que concerne a responsabilidade em caso de violação aos direitos dos consumidores, tendo em vista que as celebridades são partes integrantes da cadeia de consumo, figurando ao lado de todos os outros agentes. (GUIMAR ÂES, 2001, p. 98)

Guimarães veio ainda a expor o entendimento do Tribunal de Alçada de Minas Gerais que decidiu que

[...] a teoria da confiança atribui responsabilidade àquele que, por seu comportamento na sociedade, gera no outro contratante justificada expectativa no adimplemento de determinadas obrigações. A publicidade integrará o contrato, de acordo com o art. 30 do CDC. (GUIMARÃES, op. cit., p. 167.)

$\grave{A}$ vista disso, dentre as regras que objetivam proteger o consumidor e promover a obtenção de seu ressarcimento pelos danos que lhes foram causados, se destaca a solidariedade da cadeia de fornecimento, contida no art. Art. $7^{\circ}$, parágrafo, do $\mathrm{CDC}$, que preconiza: "Parágrafo único. Tendo mais de um autor a ofensa, todos responderão 
solidariamente pela reparação dos danos previstos nas normas de consumo" (BRASIL, 1990), o que importa em dizer que, sendo necessária a reparação de danos, todos aqueles que estejam envolvidos na cadeia de consumo irão responder de forma solidária, podendo a obrigação ser exigida de qualquer um dos integrantes da cadeia.

Logo, percebe-se que deve o influenciador responder solidariamente com a marca contratante, fornecedora de bens/serviços, equiparado a um fornecedor, uma vez que ele atua como um veículo direto da publicidade, que é postada normalmente nas suas mídias sociais de uso pessoal, devendo responder, portanto, de forma objetiva e solidária. Essa solidariedade visa proteger os direitos inerentes aos consumidores, que poderão exigir o cumprimento da obrigação de mais de uma pessoa, aumentando as chances de que a obrigação seja efetivamente cumprida. (MIRAGEM, 2014)

Há alguns debates sobre a hipótese de reconhecimento da responsabilidade civil subjetiva do Influenciador Digital, porém, este teria que ser enquadrado como um profissional liberal, que, nas palavras de Nery Junior e Rosa Nery (2008), é a pessoa física que desempenha atividade remunerada em favor de outrem, sem manter perante aquele que o remunera, qualquer vínculo de subordinação, devendo se enquadrar no que preceitua o art. 14, $\S 4^{\circ}$, do Código de Defesa do Consumidor. Entretanto, os influenciadores não se encaixam nessa definição, uma vez que eles são contratados não em razão de possuírem uma qualidade técnica e intelectual, mas sim do seu engajamento e popularidade nas redes sociais. Além disso, esses profissionais não são escolhidos pelos consumidores, mas sim impostos pelos anunciantes. (GUIMARÃES, 2001)

Isto posto, a maior parte dos estudiosos do tema entendem que, pelo que rege o Código de Defesa do Consumidor, a responsabilidade civil se apresente presumidamente objetiva, em razão da conduta do agente, razão pela qual a regra é a aplicação da responsabilidade objetiva, ou seja, não há avaliação de culpa na conduta do agente, dando-se essa responsabilidade de forma solidária e equiparada. (FROTA, 2013)

\section{CONSIDERAÇÕES FINAIS}

A publicidade é um importante fator de desenvolvimento da economia mundial e do mercado de consumo, podendo ser utilizada como um meio informativo e que é detentor de poder, capaz de alterar o comportamento de compra dos consumidores, e, 
com a sua expansão dentro do campo digital, surge a figura do Influenciador Digital. Com isso, foi feito um levantamento crítico, na seção de número 3, acerca da maneira em que os consumidores são colocados em posição vulnerável pelos influenciadores, de tal forma que acabam tendo prejuízos com as publicidades testemunhais destes últimos, situação em que a justificativa do trabalho se revelou importante para a reflexão e a busca pela compreensão, de como o direito poderia agir para proteger os direitos lesados dos consumidores e melhorar a eficácia das relações jurídicas e das experiencias com o consumo digital.

O objetivo geral dessa pesquisa foi investigar, sob uma perspectiva jurídica, como se dá a responsabilidade civil do influenciador digital na sociedade de consumo, como forma de responder a problemática aqui estabelecida. Já os objetivos específicos se resumiram em compreender o fenômeno do influenciador digital e sua inserção no mercado de consumo, examinar, por meio das fontes do direito, a possibilidade de responsabilização dos influenciadores e apresentar o corolário da responsabilidade civil do influenciador digital. Os resultados obtidos a respeito dos objetivos se mostraram positivos, conforme as seções de números 2 e 4 , onde foi perfeitamente possível entender desde o papel do influenciador até a sua responsabilização, em que ficou evidenciado, que ele pode, sim, ser responsabilizado e que essa responsabilidade se efetiva de maneira objetiva e solidária, em que a figura do influenciador atua equiparado a um fornecedor de bens ou serviços, pelos reparos aos danos circunstanciais causados aos consumidores.

Conclui-se também, que a metodologia empregada a esta pesquisa se mostrou perfeitamente eficaz, no entanto, poderia se tornar mais salutífera, no sentido de trazer a opinião dos consumidores sobre o tema pautado, para que fosse demonstrada a realidade sobre a vulnerabilidade do consumidor com mais clareza e riqueza de evidências, para que em um futuro não tão distante, com a amplitude que a internet vem alcançando, possa haver regulamentos específicos que busquem proteger e zelar pelos direitos dos consumidores na internet, de uma forma mais genuína e mitigada.

\section{REFERÊNCIAS}

ALMEIDA, Marcos Inácio Severo de et al. Quem Lidera sua Opinião? Influência dos Formadores de Opinião Digitais no Engajamento. Revista de Administração Contemporânea. Rio de Janeiro: ANPAD, 2018, v. 22, n. 1, p. 16. 
BRASIL. Constituição (1988). Constituição da República Federativa do Brasil. Brasília, DF: Senado Federal: Centro Gráfico, 1988.

BRASIL. Lei no 10.406 de 10 De Janeiro De 2002, Código Civil. Diário Oficial da União. Brasília, DF: Senado Federal: Centro Gráfico, 2002.

BRASIL, Lei no 8.078 de 11 de Setembro de 1990, Código de Defesa do Consumidor. Diário Oficial da União. Brasília, DF: Senado Federal: Centro Gráfico, 1990.

CONAR - Código Brasileiro de Autorregulamentação Publicitária, diretrizes da legislação publicitária do País, especialmente capituladas na Lei no 4.680, de 18 de junho de 1965, e no Decreto $\mathrm{n}^{\circ}$ 57.690, de $1^{\circ}$ de fevereiro de 1966. Disponível em: http://dlm.fflch.usp.br/sites/dlm.fflch.usp.br/files/Anexo\%20A\%20\%20C\%C3\%B3digo \%20CONAR.pdf. Acesso em 06 dez. 2020.

DEL MASSO, Fabiano. Direito do Consumidor e Publicidade Clandestina: uma análise jurídica da linguagem publicitária. Rio de Janeiro: Elsevier, 2009, p. 90.

DICIONÁRIO INFORMAL. Boca-a-boca. Disponível em: https://www.dicionarioinformal.com.br/boca-a-boca/. Acesso em 13 mai. 2021.

GASPARATTO, Ana Paula Gilio; FREITAS, Cinthia Obladen de Almendra; EFING, Antônio Carlos. Responsabilidade civil dos influenciadores digitais. Revista Jurídica Cesumar janeiro/abril 2019, v. 19, n. 1, p. 72.

GIL, Antônio Carlos. Métodos e técnicas de pesquisa social. São Paulo, $6^{\circ}$ ed. Editora Atlas S.A - 2008.

GUIMARÃES, Paulo Jorge Scartezzini. A publicidade ilícita e a responsabilidade civil das celebridades que dela participam. Revista dos Tribunais, 2001. p.196.

GUIMARÃES, Paulo Jorge Scartezzini. A Publicidade ilícita e a responsabilidade civil das celebridades que dela participam. São Paulo: RT, 2001. p. 98.

HUGO GLOSS, Nathalia Duarte. Instagram Divulga Ranking dos 'Stories' Populares no mundo e Carlinhos Maia só Perde para Kardashian; Confira! Disponível em: https://hugogloss.uol.com.br/buzz/tech/instagram-divulga-ranking-dosstories-populares-no-mundo-e-carlinhos-maia-perde-para-kardashian-confira/ Acesso em: 13 mai. 2021

KARHAWI, Issaaf. Et al. Influenciadores digitais: O Eu Como Mercadoria. In: SAAD, Elizabeth; SILVEIRA, Stefanie C. (org.). Tendências em comunicação digital. São Paulo: ECA/USP, p. 39-58, 2016, p. 46-47. Disponível em: http://www.livrosabertos.sibi.usp.br/portaldelivrosUSP/catalog/download/87/75/3651?inline=1. Acesso em: $06 \mathrm{dez} .2020$.

KLICKPAGES, Hugo Rocha. Facebook Ads: tudo o que você precisa saber para anunciar na maior rede social do mundo. Disponível em: https://klickpages.com.br/blog/facebook-ads-o-que- 
e/\#: :text=O\%20Facebook\%20Ads\%20\%C3\%A9\%20um,que\%20forma\%20isso\%20va i\%20acontecer. Acesso em 13 mai. 2021.

MARQUES, Cláudia Lima, BENJAMIM, Antônio H. V., BESSA, Leonardo Roscoe. Manual de direito do consumidor. São Paulo: Revista dos Tribunais, 2007, pág. 83 MIRAGEM, Bruno. Curso de direito do consumidor. 5.ed. São Paulo: Editora Revista dos Tribunais, 2014. p. 570-571.

MUNIZ, Eloá. Publicidade e Propaganda Origens Históricas. Caderno Universitário, Nº 148, Canoas, Ed. ULBRA, 2004.

NERY, Nelson Junior; NERY, Rosa. Código de Processo Civil comentado cit.; Antônio Herman de Vasconcellos Benjamin, op. cit., p. 80; e Cláudio Bonatto e Paulo Valério Dal Pai Moraes, op. cit., p. 128.

OFUXICO, Michele Marreira. Carlinhos Maia Ultrapassa 2 Bilhões De Impressões No Instagram. Disponível em: https://www.ofuxico.com.br/noticias-sobrefamosos/carlinhos-maia-ultrapassa-2-bilhoes-de-impressoes-no-instagram/2020/08/24384384.html Acesso em: 13 mai. 2021.

RODRIGUES, Silvio. Direito civil: responsabilidade civil. v. 4. 20. ed. São Paulo: Saraiva, 2003.

TICIANELli, Marcos Daniel Veltrini. Delitos Publicitários no Código de Defesa do Consumidor e na Lei 8.137/90. Curitiba: Juruá, 2007.

VERONEZZI, José Carlos. Mídia de A a Z: conceitos critérios e formulas dos 60 principais termos de mídia, 3 ed., São Paulo, Pearson Prentice Hall, 2009.

VUlgata COMUNICAÇÃO E MARKETING. Publipost: como funciona? Disponível em: https://agenciavulgata.com.br/publipost-como-funciona/ Acesso em: 13 mai. 2021.

\section{Recebido em: 05/11/2021}

Aprovado em: 02/12/2021 